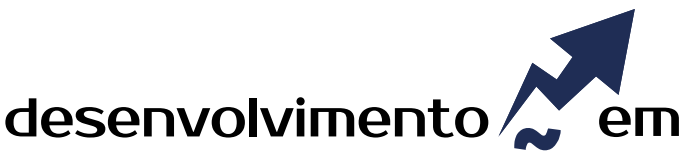 QUESTÃO
}

\section{Capital Social e Políticas de Desenvolvimento Territorial: Estudo Multicasos nos Territórios da Cidadania do Rio Grande do Norte}

\author{
http://dx.doi.org/10.21527/2237-6453.2019.46.163-180
}

Recebido em: 26/5/2017

Aceito em: 16/8/2018

\author{
Yuri de Lima Padilha, ${ }^{1}$ Washington José de Souza ${ }^{2}$
}

\begin{abstract}
RESUMO
Este trabalho objetiva avaliar elementos de capital social que circundam o Programa Territórios da Cidadania no Rio Grande do Norte. Diferentemente de outras investigações sobre o tema, não se pretende medir o estoque de capital social, mas, sim, revelar o fenômeno da organização social e suas implicações, considerando que os territórios são constituídos pela política ao redor de estruturas de fomento ao capital social, qual seja, os colegiados territoriais, arenas que comportam representantes das diversas instâncias do poder público e da sociedade civil. A noção de capital social está na existência de relações que permeiam e sustentam o processo de desenvolvimento de forma institucionalizada, normatizadas ou articuladas sob a forma de rede social (COSTA, 2005). Os estudos e as definições clássicas de capital social estão em Bourdieu (1986), Coleman $(1990,2000)$ e Putnam (2008). Este trabalho tem caráter qualitativo e fez uso do estudo de caso como estratégia de pesquisa. A coleta de dados aconteceu mediante entrevista semiestruturada ou semipadronizada. Para tanto foram escolhidos representantes das instituições públicas e sociais envolvidos nos colegiados territoriais do Açu-Mossoró, Mato Grande e Sertão do Apodi. O modelo de análise e interpretação dos dados foi estruturado a partir da Análise de Conteúdo categorial de Bardin (2004). Nos casos em pauta, em que pese a similaridade das condições gerais de estrutura e funcionamento, o Sertão do Apodi apresenta qualidades superiores aos demais tendo em vista sua trajetória de cooperação e articulação social em torno da assistência técnica, aspecto histórico do território.
\end{abstract}

Palavras-chave: Capital social. Desenvolvimento territorial. Políticas públicas.

SOCIAL CAPITAL AND TERRITORIAL DEVELOPMENT POLICIES: STUDY IN THE TERRITORIES OF CITIZENSHIP IN RIO GRANDE DO NORTE.

\begin{abstract}
This paper aims to evaluate elements of social capital in Territory of Citizenship Program in Rio Grande do Norte. Unlike other investigations in the theme, it is not intended to measure the stock of social capital, but rather to reveal the phenomenon of social organization and its implications, considering that the territories are constituted by the politics around structures of foment to social capital, which Be they territorial colleges, arenas that include representatives of the various levels of government and civil society. The notion of social capital is in the existence of relations that permeate and sustain the development process in an institutionalized way, normalized or articulated in the form of a social network (COSTA, 2005). The classical studies and definitions of social capital are in Bourdieu (1986), Coleman $(1990,2000)$ and Putnam (2008). This work has a qualitative character and made use of the case study as the research strategy. Data collection was done through a semi-structured or semipadronized interview. For this purpose, were chosen representatives of the public and social institutions involved in the Açu-Mossoró, Mato Grande and Sertão do Apodi regions. The data analysis and interpretation model was structured from the categorical content analysis of Bardin (2004). In the cases in question, despite the similarity of the general conditions of structure and functioning, the Sertão do Apodi presents qualities superior to others in view of its trajectory of cooperation and social articulation around the technical assistance, historical aspect of the territory.
\end{abstract}

Keywords: Social capital. Territorial development. Public policy.

\footnotetext{
${ }^{1}$ Mestre em Administração pela Universidade Federal do Rio Grande do Norte (UFRN). Doutorando em Administração pela Universidade Federal do Rio Grande do Norte (UFRN). Professor do Instituto Federal do Rio Grande do Norte (IFRN), campus Macau. yuri.padilha@gmail. com

${ }^{2}$ Doutor em Educação pela Universidade Federal do Ceará (UFC). Professor titular do Departamento de Administração Pública e Gestão Social (DAPGS) da Universidade Federal do Rio Grande do Norte e professor do Programa de Pós-Graduação em Administração da Universidade Federal do Rio Grande do Norte (UFRN).wsouza@ufrnet.br
} 
Este trabalho objetiva avaliar elementos de capital social que circundam o Programa Territórios da Cidadania no Rio Grande do Norte. Os "territórios da cidadania" foram criados a partir de critérios que demonstravam baixo acesso a serviços básicos, índices de estagnação na geração de renda e carências de políticas integradas e sustentáveis para autonomia econômica de médio prazo (DELGADO; BONNAL; LEITE, 2007). De acordo com documento da Secretaria do Desenvolvimento Territorial, órgão do Ministério do Desenvolvimento Agrário (SDT/MDA), responsável pelas ações públicas territoriais, a abordagem territorial justifica-se por vários aspectos, entre os quais: a) o rural não se resume ao agrícola; b) a escala municipal é muito restrita ao planejamento e à organização de esforços visando à promoção do desenvolvimento, enquanto a escala estadual é excessivamente ampla; c) a necessidade de descentralização das políticas públicas; d) o território é a unidade que melhor dimensiona laços de proximidade entre pessoas, grupos sociais e instituições, estabelecendo iniciativas voltadas para o desenvolvimento. Nesse contexto, articulam-se políticas públicas setoriais a fim de universalizar o acesso aos programas básicos de cidadania e, sobretudo, estimula-se a participação social e o protagonismo de atores no ciclo da gestão das políticas públicas. A participação social, portanto, é componente básico, aliada à articulação e à integração de políticas, e se concretiza, como espaço institucional, nos colegiados territoriais. Os colegiados territoriais são arenas que comportam representantes das diversas instâncias do poder público e da sociedade civil no intuito de gerar inovação coletiva, evitar assimetria de informação e garantir efetiva gestão compartilhada.

Embora os Territórios da Cidadania tenham sido estabelecidos pelo MDA a partir dos mesmos critérios normativos, apresentam diferentes Índices de Condições de Vida (ICVs, indicador utilizado pelo MDA para medir desenvolvimento): Mato Grande, ICV baixo; Açu-Mossoró, ICV médio e Sertão do Apodi, ICV alto. Escolheu-se o capital social como elemento teórico-empírico para esta pesquisa em virtude da sua centralidade na política dos Territórios da Cidadania. Ademais, o construto capital social é componente teórico válido à interpretação do fenômeno do desenvolvimento territorial, pois são a ele comumente referenciados, entre outros temas como redes sociais ou relações sociais voltadas a objetivo comum, cooperação, confiança e reciprocidade, além de acesso à informação. Estes elementos traduzem-se na capacidade de auto-organização de comunidades que, de certa forma, contribuem para a superação de dilemas em torno de ações de interesse coletivo na medida em que atores qualificados interagem e compartilham vivências e cooperam em projetos comuns, favorecendo inovações em termos individuais e coletivos.

A pesquisa está focada em fatores de capital social, envolvendo atributos como participação e articulação de atores, acesso à informação e diversidade de atores e interações em redes sociais, haja vista que se assume o entendimento que capital social é fator inerente à coletividade e está fundado em estruturas de relacionamento de indivíduos e grupos. Diferentemente de outras investigações no tema, não se pretende medir o estoque de capital social, mas, sim, revelar o fenômeno da organização social e suas implicações, considerando que os territórios são constituídos pela política ao redor de estruturas de fomento ao capital social, qual seja, os colegiados territoriais, arenas que congregam representantes das diversas instâncias do poder público e da sociedade civil. 


\section{DESENVOLVIMENTO TERRITORIAL E POLÍTICAS PÚBLICAS}

A definição de políticas públicas que se utilizam do território como lócus operacional contempla duas importantes vantagens, quais sejam, a possibilidade de agir na qualidade de vida e condição social de habitantes, indo além das ações com foco em grupo de beneficiários e o território como mote da articulação de diferentes projetos e políticas, a fim de garantir a sinergia e a efetividade das intervenções locais (BUARQUE, 2012).

O processo de descentralização presente na abordagem territorial propicia desenvolvimento na medida em que assume "como objetivo central a criação de institucionalidades e a articulação de atores e de políticas públicas que favoreçam o desencadeamento de dinâmicas endógenas capazes de sustentar processos de desenvolvimento territorial" (DELGADO; BONNAL; LEITE, 2007). Por esta razão, Buarque (2008) alega que o desenvolvimento local ou territorial satisfatório depende da capacidade de estruturação e mobilização de atores em vista da conjuntura, a fim de explorar prioridades e potencialidades específicas. Nessa perspectiva, as políticas públicas por si não são suficientes para atender demandas sociais e suas problemáticas sem a cooperação social (CASTELLS; BORJA, 1996). É a descentralização que proporciona a institucionalização, revelando-se condição elementar para a interação de atores sociais por intermédio da constituição de espaços públicos como conselhos, fóruns e colegiados. Outrossim, o desenvolvimento territorial não pode ser entendido como resposta endógena a problemas exógenos. Por isso, a importância da densidade institucional formada em torno da estratégia de desenvolvimento territorial reúne atores e instituições de diversas instâncias para elencar de forma mais ampla e coletiva as demandas e potencialidades do território, o que torna os atores mais ativos na intervenção, refletindo-se no desencadeamento de processos de desenvolvimento territorial (RÜCKERT; RAMBO, 2007).

Diante disto, é necessário que se observe o modo como os territórios são capazes de constituir espaços de ampliação de práticas democráticas, tendo o Estado papel relevante na mobilização e no provimento de recursos necessários (FLORES, 2007). Deve-se observar que é comum que os processos participativos legitimem poderes dominantes e inibam formas inovadoras e inclusivas de recursos (ABRAMOVAY, 2005). Essa disfunção é facilmente sustentada por outro problema, comumente ignorado durante o processo de descentralização e criação de institucionalidades, que é o frágil preparo dos atores sociais. No geral, as organizações de representação da agricultura familiar são insuficientes em número, pouco representativas e têm baixa capacidade de mobilização social. Essas características limitam a ação de estratégias de desenvolvimento (NAVARRO, 2001).

Nos espaços institucionais de participação e representação, torna-se, então, imprescindível que se fomente capital social, também compreendido como capacidade de se auto-organizar (PUTNAM, 2008), pois fatores econômicos tradicionais não mais são considerados explicativos suficientes para o desenvolvimento, a mobilização de atores e a formação de redes entre organismos e instituições locais tornam-se formas de inserção produtiva e de atenuação das desigualdades sociais (MULS, 2008). 


\section{CAPITAL SOCIAL: Estrutura e Feitos em Processos de Desenvolvimento}

A noção de capital social está na existência de relações que permeiam e sustentam o processo de desenvolvimento de forma institucionalizada, normatizada ou articulada sob forma de rede social (COSTA, 2005). Os estudos e as definições clássicas de capital social estão em Bordieu (1986), Coleman (1990, 2000) e Putnam (2008).

Para Bourdieu (1989), o capital social estaria ligado ao conjunto de recursos, tanto atuais quanto potenciais, oriundos de uma rede durável de relações mais ou menos institucionalizadas e de interconhecimento, ou seja, indivíduos vinculados a um grupo, unidos por ligações permanentes. Assim, as redes e suas relações são transformações de elos contingenciais, com implicações de sentimentos de obrigações duráveis ou garantias institucionais.

Coleman (1990) igualmente sustenta a compreensão de que o capital social é inerente às estruturas de relacionamento entre indivíduos e entre grupos de pessoas. 0 autor entende capital social como conjunto de recursos possuídos por determinados indivíduos e possíveis de construir uma estrutura social e facilitar a ação de indivíduos em dada região. Coleman (2000) afirma que o capital social auxilia na coesão na medida em que os indivíduos, em dada rede de contatos, interagem baseados em expectativas de reciprocidade, obediência a normas coletivas e de cooperação que promovem negociação em situações de conflito.

Na mesma linha, Putnam (2008) afirma que capital social é a capacidade que grupos e organizações detêm de trabalhar conjuntamente para objetivos comuns. O conceito compreende características da organização social - normas, confiança e sistemas que possibilitam à sociedade aumentar sua eficiência a partir de ações coordenadas. O capital social provém do envolvimento do indivíduo em atividades coletivas, o que, consequentemente, promove a construção de redes de confiança recíproca (PUTNAM, 2008).

É importante enfatizar que o capital social de uma comunidade não é a simples soma dos capitais individuais, mas a forma como os atores se organizam torna-se importante para se produzir socialmente (PORTES; LANDOLT, 1996), tendo em vista que o capital social resulta dos elos interpessoais estruturados nas redes sociais que balizam, guiam e fiscalizam o comportamento coletivo (SOARES, 2009). Como tal, ele espelha, em suas formas e dimensões, a complexidade dessas redes. Seria impossível, portanto, entender as perspectivas de políticas e projetos de desenvolvimento sem o devido conhecimento das características de uma rede social, tanto em nível micro quanto macro, bem como, de que forma esses níveis se articulam e o contexto sócio histórico de tal articulação (WOOLCOCK, 2001).

As relações formadoras das redes podem ser caracterizadas de formas distintas. As relações de ligação (bonding) referem-se a interações entre sujeitos similares quando compartilham características demográficas, entre os quais familiares, vizinhos, amigos e colegas de trabalho. As relações chamadas de ponte (bridging) são aquelas interações entre sujeitos que não compartilham de características similares. Há também as relações de conexão (linking), que se referem a laços mantidos por pessoas que detêm posições de autoridade, tais como representantes de instituições públicas e privadas. A 
diferenciação entre o capital social de ponte e o de conexão é feita em virtude da posição relativa dos indivíduos na escala de poder, político ou econômico: no primeiro, as ligações são horizontais, entre iguais ou pares; no segundo, elas são verticais, de um estrato para outro, ligando indivíduos entre os quais a diversidade de posição estabelece uma relação de poder, de um lado, dependência ou subordinação, do outro. Cada tipo de capital social tem características particulares. O capital social de ligação age como apoio seguro de redes; o de ponte permite a pessoas de diferentes redes terem acesso às oportunidades e a terceira forma, de permitir que pessoas e comunidades tenham melhorias no nível de vida e de infraestrutura (BANCO MUNDIAL, 2003; STOLLE, 2003).

As redes de atores são suportes em termos de recursos físicos e informacionais, bem como a possibilidade de desenvolver sentimentos de inclusão dentro de um projeto. É este apoio social que proporciona suporte para a consecução de recursos e para medir e ampliar oportunidades, reduzindo incertezas (WELLMAN; FRANK, 2001). Por estas características ele é considerado um recurso que possibilita, associado a outros elementos, o crescimento endógeno de uma comunidade.

As relações sociais maximizam o capital social, ao passo que, quanto mais pessoas se encontram envolvidas, maior o capital social, visto que a ampliação de atores maximiza a rede e a disseminação de informações, permitindo o crescimento da comunidade (PUTNAM, 2008). A comunicação e a informação geradas por este processo têm importância em virtude da diminuição de custos transacionais proporcionados pelo compartilhamento e a consequente redução da assimetria da informação e do risco moral. Há também o reconhecimento mútuo de identidade entre os membros e a geração de influência legitimada (LIN, 2001). Além disso, é importante compreender que o processo de comunicação e informação gerado em estruturas formadoras de capital social influencia o desenvolvimento, na medida em que estes processos representam o meio pelo qual a comunidade tem acesso a informações relativas às condições do mercado e de serviços públicos (BANCO MUNDIAL, 2003).

A comunicação pode apresentar-se em diferentes níveis, segundo os tipos de relações estabelecidas: comunicação entre os próprios membros da comunidade, para que se possa alcançar objetivos comuns; comunicação entre comunidades; comunicação entre comunidades e o Estado. Segundo Soares (2009), "cada nível representa um elo da malha em que a comunidade está inserida, havendo, pois, um tecido social que os une".

A informação é fundamental para promover a coesão e o consenso nas redes, tendo em vista que a partilha da informação de modo igual fortalece a confiança e, portanto, a cooperação no grupo. Ainda, a interação e o diálogo consequente produzem clareza e ajudam a delimitar os objetivos comuns, de forma a facilitar o alcance, na medida em que se legitimam ante todo o grupo, haja vista que as prioridades são determinadas democraticamente. A informação também detém a função de impor regras morais, mas, às vezes, não é suficiente para cumprir essa função, e, aí, surgem as regras legais, com custos de transação.

A maior virtude do capital social, quanto à geração de benefícios, está na confiança, que não é propriedade de indivíduos ou instituições, mas produzida nos espaços sob influência da capacidade associativa (WALLIS; DOLLERY, 2002). Esta é geradora de ação coletiva e cooperação - forma como a comunidade trabalha em conjunto, como funcionam projetos comunitários e como há controle daquelas pessoas que procuram 
benefícios sem trabalhar, ou melhor, como funcionam regras morais na comunidade para aqueles que as infringem. O fortalecimento da confiança perpassa a conduta da reciprocidade ao passo que o indivíduo nutre a expectativa de que sua ação seja retribuída e, por isso, Atria (2003) elucida estes termos e, assim, postula que "a confiança, a reciprocidade e a cooperação são os recursos associativos que servem para dimensionar o capital social. A confiança é o resultado acumulado da iteração da integração de pessoas que aceitaram correr risco em torno de um sentimento de afetividade ou de identidade. A reciprocidade está ligada ao princípio orientador de uma lógica de interação alheia à lógica do mercado, que envolve troca de favores. A cooperação é a ação complementar orientada à conclusão de objetivos compartilhados e de um entendimento comum".

Para Fukuyama (1996), a confiança é igualmente condição fundamental ao capital social, ao passo que ele só se sustenta enquanto a confiança prevalece, pois grupos são formados independentemente da relação de confiança. Capital social, todavia, requer normas e virtudes individuais e coletivas. As normas, que podem ser formais (legais) ou informais (regras não escritas), são mais ou menos claras de acordo com o grupo que as aplica. Tendo em vista que as normas derivam da ação social e não são iguais em todos os grupos, a influência sobre o desenvolvimento não vai ser a mesma (PORTELA; NEIRA, 2012).

Neste ponto, destaca-se o papel do Estado para a construção do capital social, tendo em vista a sua legitimidade como gestor da sociedade, pois só ele tem o poder de impor leis que substituam convenções não escritas. O capital social está presente na descentralização do Estado mediante parcerias com comunidades, repassasses de responsabilidades e atribuição de tarefas. De acordo com Woolcock e Narayan (2002), a integração entre redes sociais com instituições públicas, e até mesmo privadas, é medida complementar à representação da comunidade. Ademais, circunda a discussão do capital social e sua relação com as instituições públicas, a necessidade de empoderar as comunidades.

Para Schmidt (2003), o capital social, como mobilizador da organização social, seria fator essencial ao Estado para que este possa estar mais próximo do povo, fortalecendo a presença da população nos espaços de decisão pública. $O$ investimento em capital social e na organização social em si prevê retornos positivos, mas a eficácia do investimento pressupõe capacidade de coordenação da comunidade, o que depende da coesão em torno de uma identidade comum, dada, geralmente, por laços culturais que facilitam a cooperação em torno de objetivos comuns (LIN, 2001). A importância da cultura está na influência para o fortalecimento do capital social, pois os mecanismos culturais são seus transmissores (FUKUYAMA, 1996). Nesse sentido, Kliksberg (2002) afirma que "A cultura cruza todas as dimensões do capital social de uma sociedade. Ela fica subjacente aos componentes básicos considerados capital social, como a confiança, o comportamento cívico e o grau de associativismo". Esta situação é também retratada por Putnam (2008), quando discute capital social e democracia a partir da influência da cultura cívica em regiões da Itália.

A cultura está relacionada com o capital social, tendo em vista que a história é importante para a análise e avaliação dos resultados das organizações. Este é um pressuposto da dependência de trajetória, abordagem que considera a trajetória de uma orga- 
nização como definidora do desenvolvimento de recursos e capacidades. Isso ocorre por que a experiência vivida pode facilitar conquistas futuras. Desse modo, as ações passadas afetam nas estratégias deliberadas, mostrando-se importante compreender eventos críticos na trajetória da organização social (BARNEY, 1995, 2001; MINTZBERG; WATERS, 1985). A trajetória, contudo, não é unicamente determinante no desenvolvimento de uma organização. Torna-se importante perceber a criação de trajetória, realizada a partir da análise dos atores em suas relações e do processo de inovação fomentado nestas interações (BITENCOURT; OLIVEIRA, 2014). Dependência de trajetória e criação de trajetória, portanto, são processos complementares.

\section{PROCEDIMENTOS METODOLÓGICOS}

Este trabalho tem caráter qualitativo e fez uso do estudo de caso como a estratégia de pesquisa, pois permite compreensão a partir de investigação que atribui características holísticas e significativas a eventos no contexto da vida real (YIN, 2001). Considera-se aqui a utilização de casos múltiplos.

Foram escolhidos representantes das instituições públicas e sociais envolvidos nos três colegiados territoriais - Açu-Mossoró, Mato Grande e Sertão do Apodi. Especificamente, aqueles do núcleo diretivo, foram selecionados a partir do critério de envolvimento mais efetivo na estrutura, no funcionamento e nas reuniões. Estes detêm dados mais consistentes acerca da ação pública do território. Além disto, a escolha dos sujeitos em virtude da participação no colegiado se dá tendo em vista que o capital social é produzido e influencia a ação destes atores neste espaço institucional legitimado para a articulação e instituição de políticas públicas que visam ao desenvolvimento territorial. Os sujeitos desta pesquisa foram: um representante do poder público; um representante da sociedade civil; um representante de entidade de apoio e fomento e o articulador territorial de cada um dos territórios.

A coleta de dados aconteceu mediante entrevista semiestruturada ou semipadronizada, haja vista que esta possibilita que a postura do entrevistado acerca do tema torne-se mais explícita, podendo ser desenvolvida, segundo o princípio da abertura, para trazer à tona o conhecimento implícito do entrevistado. Ou seja, esta técnica permite a exploração, em profundidade, da perspectiva dos atores sociais, consequentemente, melhor apreensão e compreensão das condutas e dilemas enfrentados pelos atores em sua realidade. Operacionalmente, isto é possível em virtude de as questões da entrevista serem feitas a partir da teoria, sendo produto tanto direto da literatura científica quanto de pressupostos teóricos do pesquisador (FLICK, 2009; POUPART, 2008). O modelo de análise e interpretação dos dados foi estruturado a partir da Análise de Conteúdo categorial de Bardin (2004).

As categorias de análise que serviram de orientação para coleta de dados e consequente análise estão descritas no quadro a seguir: 
Quadro 1 - Categorias de Análise

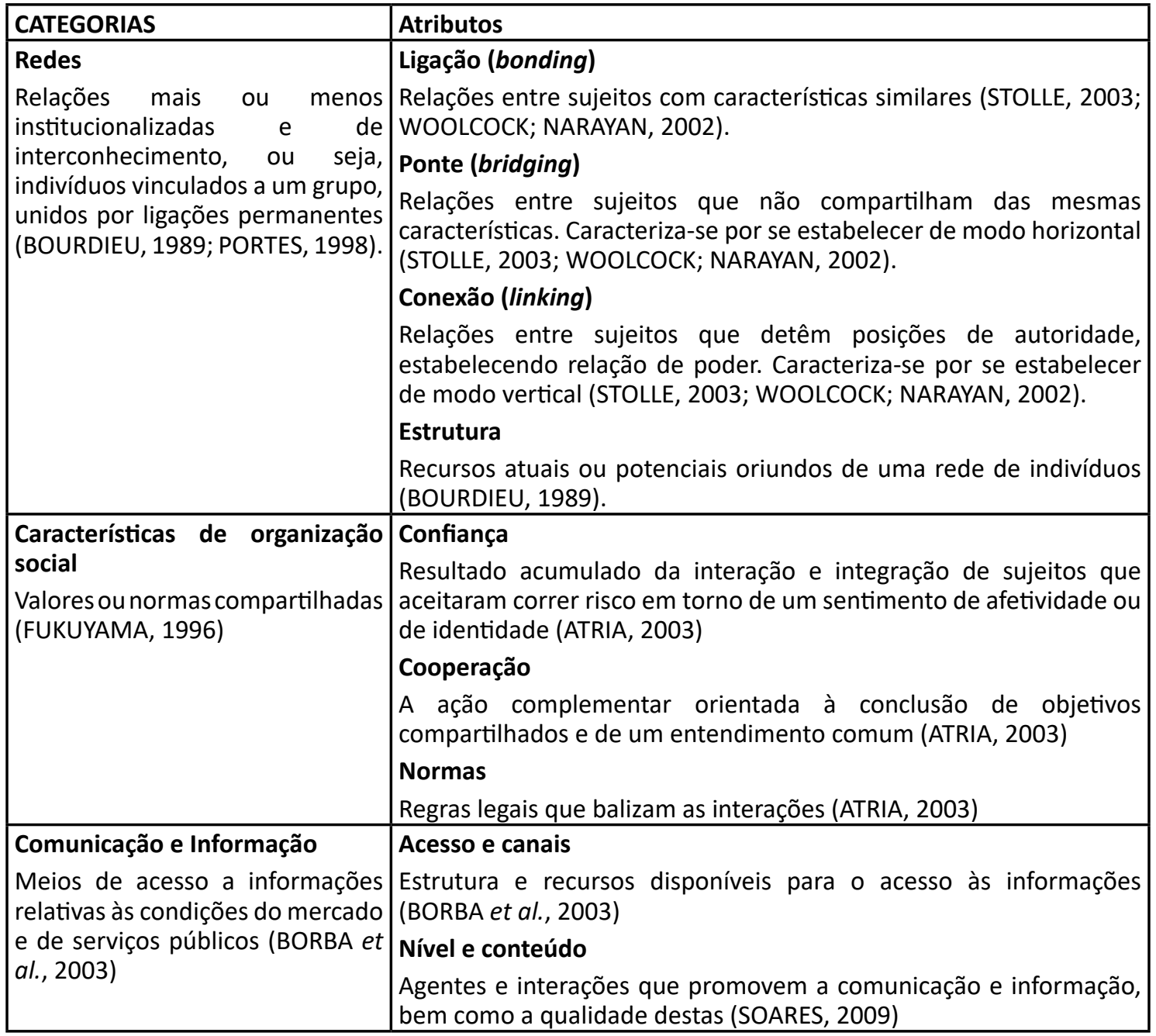

Fonte: Elaborado pelos autores.

A partir destas categorias teóricas que representam elementos de capital social, algumas questões orientadoras foram definidas para as entrevistas, quais sejam:

- Quais atores têm maior atuação e participação no território/colegiado?

- Existem atores que são estratégicos no território, mas que não estão envolvidos no colegiado?

- Há algum projeto que tenha integrado dois ou mais municípios do território como objeto de articulação a partir do funcionamento do colegiado?

- Como você avalia os efeitos e a implementação das decisões tomadas no colegiado?

- Quais as principais dificuldades para desenvolvimento do território, bem como das ações do colegiado?

- Como você avalia a cooperação entre os atores territoriais?

- Como os representantes do colegiado comunicam as discussões e decisões às bases?

- Que entidades (de qualquer tipo, sociedade civil, assistência técnica ou poder público) se destacam no acesso à informação, na capacitação e na assistência técnica no território? 
Durante a elaboração da pesquisa alguns critérios que possibilitam validação e confiabilidade foram observados na construção dos seus procedimentos de entrada no campo e no processo de análise. Os autores deste trabalho já atuavam no campo da pesquisa - colegiados territoriais - como pesquisadores e membros muito antes da coleta de dados e continuaram nele após a realização das entrevistas. Sendo assim, houve a verificação do que foi coletado nas entrevistas, bem como o tempo de campo possibilitou reflexividade na construção das análises, possível pela inserção na interação com os sujeitos e pelo acúmulo de conhecimento sobre o funcionamento desta política pública em particular. A escolha dos sujeitos de pesquisa também possibilitou triangulação e validação em virtude de trazer informações de atores oriundos de grupos diferentes, além de serem escolhidos pelo envolvimento do núcleo diretivo de cada colegiado, o que determina que sua vivência permite informações consistentes que, somadas à presença dos pesquisadores no campo, garante confiabilidade aos dados. Verifica-se, também, que as questões da entrevista não estabeleciam, a priori, relações entre as categorias e seus atributos, o que possibilitou respostas espontâneas que se tornam confiáveis em virtude dos cuidados anteriormente citados.

\section{ANÁLISE DE DADOS}

Os dados foram analisados a partir de elementos de capital social elucidados em três categorias: redes, características de organização social e comunicação e informação. Estas categorias apresentam interdependência, ao passo que a análise individual de cada uma delas fragmentaria a visualização do objeto desta pesquisa. Apesar disso, o texto que segue acompanha a apresentação anterior das categorias e finaliza com um quadro sintético das evidências e suas análises.

No que diz respeito à formação de redes de relacionamento nos Territórios da Cidadania em pauta - Açu-Mossoró, Mato Grande e Sertão do Apodi - há ênfase nas relações de ligação, isto é, na interação entre indivíduos com características similares. São representantes da sociedade civil, especificamente, de associações e cooperativas de agricultores familiares, bem como de sindicatos de trabalhadores rurais. É perceptível também significativa relação de ponte, isto é, sujeitos não similares em relação de horizontalidade, visível nas entidades de apoio e fomento e sua interação constante com produtores rurais. Já as interações de conexão são mínimas nos três territórios. Essa relação vertical, e com posição de autoridade, faz-se presente a partir da atuação do poder público e de órgãos e instituições públicas envolvidos nas políticas territoriais. O poder público, contudo, é ator com restrita participação.

As interações de conexão são importantes para influenciar níveis de qualidade de vida e melhorias da infraestrutura das comunidades (BANCO MUNDIAL, 2003; STOLLE, 2003). No caso dos Territórios da Cidadania, esta influência é notável, pois o programa, criado justamente para melhorias de condições de vida, tem em seu desenho institucional o incentivo à participação e ao empoderamento da sociedade civil, mas, ao mesmo tempo, dependência dos poderes públicos na execução dos objetivos das políticas públicas que passam pelos colegiados. Assim sendo, a ausência do poder público nas discussões territoriais é fator complicador para o desenvolvimento das ações, quando enfraquece as interações de conexão, fato reconhecido por representantes de todos os territórios. 
Além da operacionalização, a ausência do Estado prejudica a formação de capital social, pois seu papel legitimador o torna fundamental na construção e indução, o que ocorre por meio de leis e regras, de relações de cooperação e de atividades descentralizadas quando há repasse de responsabilidades - é fato que o Estado, por intermédio da administração pública em todas as esferas, é o ator com tal autoridade. Por isso, Woolcock e Narayan (2002) destacam o papel desta interação entre Estado e comunidade em sua dimensão democrática, ao nível de conexão.

Ademais, questionou-se acerca do processo de gestão territorial, institucionalizado no colegiado, para compreender se as normas vigentes favorecem a formação de capital social. Nos territórios pesquisados a confiança em torno da política territorial é insatisfatória. A restrita efetividade nas decisões e na realização de projetos é um dos principais fatores apontados pelos atores para o limitado nível de confiança.

A cooperação é frágil nos territórios analisados em vista do desenho institucional em torno da política. O colegiado é espaço de discussão e debates, mas não possibilita efetivo planejamento e nem a execução dos objetivos da política a partir do envolvimento e integração dos atores, especialmente em virtude de dois fatores: o poder público não participa como seria desejável e, além disso, a ele compete, em âmbito municipal, a execução dos recursos destinados aos territórios, reforçando os resultados do ICV (Índice de Condições de Vida, indicador utilizado pelo MDA para medir desenvolvimento): Mato Grande, ICV baixo; Açu-Mossoró, ICV médio e Sertão do Apodi, ICV alto. As características da organização social tendem a seguir padrão similar. Este debate aproxima-se da proposição teórica de que são as normas, especialmente as regras formais, que induzem - favorecendo ou dificultando - à cooperação (SOARES, 2009).

O formato da política pública, por mais que tenha por intento fomentar processos descentralizados e coletivos, não tem sido efetiva neste quesito. Os atores, especialmente da sociedade civil, aproximam-se do colegiado, espaço da institucionalização da rede de atores, com expectativas de serem atendidos pelas políticas públicas e de se fazerem representados no processo de planejamento e cooperação, mas, também, de normas que sustentam expectativas. Isto ocorre em virtude do afastamento do poder púbico da política, além da mínima participação do colegiado nos processos de instituição, quando a execução está afeita às prefeituras exclusivamente, o que se configura como frágil cooperação.

Este espaço de gestão pública colegiada, quando pouco efetivo nas decisões, não é capaz, como visto nos relatos, de estimular sentimento de empoderamento, diminuindo a confiança e o interesse em participar das redes, o que enfraquece o capital social nos territórios. A relação entre empoderamento, confiança e capital social é apresentada por Schmidt (2003), quando afirma que o investimento e o cuidado nesses fatores levam à resolução dos problemas sociais e estruturais das comunidades. Sabatin (2006) contextualiza esta potencialidade, justamente, na participação da sociedade civil no ciclo de políticas públicas, realidade vista nos relatos, pois na medida em que esses atores não têm capacidade de influência, não se configuram, exatamente, como participantes.

Se a confiança dos atores é inibida, a rede, espaço estrutural de fomento ao capital social, fica prejudicada. Isto significa esvaziamento dos colegiados territoriais e enfraquecimento da política pública analisada, como previsto por Costa (2005) ao argumentar que a incerteza no cumprimento de contratos leva ao desinteresse de investidores 
por determinada região. Por sua vez, Soares (2009) observa que a geração de confiança é o que produz capital social. Ademais, ressalte-se que alguns grupos são formados independentemente da confiança e o fomento a este fator é o que garante interações, afirma Fukuyama (1996) em situação similar aos espaços aqui analisados. Afirma-se isto, pois a rede formada para interação dos atores, o colegiado territorial, é constituída como estrutura da política e não de modo espontâneo, o que reafirma a necessidade de fomento ao sentimento de confiança, pois são necessárias garantias institucionais para manutenção das relações sociais e do capital social a elas vinculado ou delas gerado.

É a partir da confiança que se faz a ação comunitária, pois dela se promove cooperação e, consequentemente, reciprocidade, conforme visto em Atria (2003). Estes fatores aparecem nas falas como suficientes, especialmente no Sertão do Apodi, denotando melhor qualidade de cooperação e confiança, e, portanto, de capital social, naquele Território. No Território Açu-Mossoró os atores também apresentam viés satisfatório em torno da cooperação e da confiança, em relação ao esforço realizado, contudo no Mato Grande as falas revelam cooperação e reciprocidade em níveis frágeis,

A cooperação, apresentada pelos sujeitos, mantém-se pela identidade que os aglutina, no caso destes territórios, a agricultura familiar e a ruralidade. Kliksberg (2002) e Lin (2001) sedimentam essa discussão propondo que cultura e identidade facilitam a coesão e a cooperação. Lin (2001), contudo, alega que a eficácia e os retornos do capital social dependem, além destas características mencionadas, da capacidade de coordenação.

É salutar destacar a importância das relações de ponte entre entidades não semelhantes, mas que estão em relação horizontal sem hierarquia entre elas. Há, aqui, colaboração, como pares, para inserção em oportunidades de desenvolvimento (BANCO MUNDIAL, 2003; STOLLE, 2003). Nos Territórios da Cidadania essas relações representam a interação entre organização de produtores e entidades de apoio e fomento, ou até mesmo entre entidades da sociedade civil com características diferentes, por exemplo, associações de produtores e ONGs envolvidas em temáticas de extensão e educação. Diante disto, questiona-se a representação de entidades de apoio e fomento e de outras da sociedade civil, em torno, apenas, da agricultura familiar no tocante à produção e à comercialização. Reconhece-se que a agricultura familiar e a ruralidade representam a identidade dos territórios, mas é sabido que tal identidade vai além do fator produtivo.

A necessidade de maior variedade de atores é sentida pelos sujeitos da pesquisa representantes dos três territórios. Eles listam instituições estratégicas para o Território, mas que estão afastados da política territorial, inibindo redes de ponte mais diversificada, quais sejam, órgãos públicos mais diretamente vinculados à agricultura familiar e Instituições de Ensino Superior próximas à rede são questionados. Há referência, portanto, às funções de ensino, pesquisa e extensão das Instituições de Ensino Superior, com destaque a órgãos da administração pública estadual e federal, o que, aliadas a outras que reclamam da ausência das prefeituras, indica fragilidades em interações sociedade civil-agentes públicos. Navarro (2001) atesta que organizações representativas da agricultura familiar têm baixa capacidade de mobilização social, além da limitação de mobilização de recursos. 
Ademais, as redes são espaços de interação de atores possibilitando trocas de recursos, materiais ou imateriais, e assim, quanto maior a diversidade de atores participando, maior a possibilidade de ações efetivas de desenvolvimento (COLEMAN, 2000). Por isto, Rückert e Rambo (2007) destacam a importância da densidade institucional ampla e diversa para que demandas e potencialidades do Território desencadeiem processos de desenvolvimento. Esse pressuposto deve fazer parte de projetos coletivos territoriais, conforme afirmam Buarque (2012) e Flores (2007), pois estes devem pautar a qualidade de vida e o fomento à sinergia de potencialidades locais a partir de uma participação ampla e democrática. Afinal, segundo Castells e Borja (1996), políticas públicas, por si sós, não são capazes de atender demandas sem cooperação social.

Os sujeitos pesquisados apresentam necessidades de ampliação da participação de atores que podem oferecer outros elementos ao desenvolvimento, além do fator produção a partir de temas e recursos como educação superior, educação básica e condição agrária e ambiental, complementares ao fomento e à consolidação de demandas dos respectivos territórios. Percebe-se que a participação deficiente é também consequência de uma frágil estrutura para sustentação das atividades dos colegiados, que representam mais consistentemente a formação de rede de atores territoriais.

Em todos os territórios existem dificuldades no custeio da estrutura para a garantia das atividades e da mobilização e articulação dos atores. Esta dificuldade compromete fatores de capital social que sustentam as redes e influenciam diretamente na efetividade do desenvolvimento, como visto em Buarque (2008), quando elenca estes elementos como condição para um desenvolvimento satisfatório. Atria (2003) igualmente propõe que estes elementos são importantes para adesão do poder à associação local. Isto significa, então, que, quanto menor o poder de mobilização, menor a participação. Sendo a participação pouco efetiva, menor o empoderamento dos atores. Dessa forma, o capital social dos territórios estaria fragilizado, pois o volume de capital social só pode ser maximizado à medida que a participação e as interações aconteçam (LIN, 2001).

O Território Sertão do Apodi possui resultados em níveis mais satisfatórios, pois paralelamente à política Territórios da Cidadania, tem a contribuição importante do Projeto Dom Helder Câmara, o qual tem assumido o papel de articular o território Sertão do Apodi, bem como de fomentar assistência técnica contínua e mobilização. Parte significativa das instituições sociais assistidas pelo Dom Helder participam do colegiado do Território da Cidadania. Há neste aspecto uma concretização dos pressupostos da dependência de trajetória, bem como de sua criação. Na medida em que o Projeto já era um ator importante de articulação e de assistência técnica anteriormente à política territorial, ele indica rumos e suporta o desenvolvimento das ações no Sertão do Apodi. Além disto, o próprio Território apresenta uma trajetória favorável às ações cooperativas e coletivas. Sobremodo, destaca-se que o Sertão do Apodi e a atuação articuladora do Projeto Dom Helder à medida que recebem uma nova investida institucionalizada - a política territorial - criam uma nova trajetória pró-Território, pois o projeto torna-se um catalizador e articulador de demandas, no Território, que potencializa capacidades de mobilização recursos e atores. Não há agente com tal consistência de ação nos outros territórios. Esta função seria do Núcleo Diretivo dos colegiados, contudo com quantidade restrita de recursos a mobilização fica comprometida. Uma contraposição expressa 
ao Território Mato Grande, que apresenta o menor nível de desenvolvimento indicado pelo ICV, é que este detém frágil estrutura para mobilização e sustentação das atividades, o que foi exposto por lideranças locais.

No que se refere aos processos de comunicação, isto é, acesso e canais, os principais meios de circulação da informação são as reuniões de base. Os atores apresentaram diversas dificuldades no acesso à informação. A maioria delas é estrutural, da própria realidade geográfica dos territórios e de estrutura das telecomunicações, bem como da indefinição de processos de comunicação dentro das redes. O esforço para utilização das telecomunicações como meio de gerar comunicação mais eficiente e eficaz, contudo, encontra entraves em virtude da própria estrutura disponível para tal nessas localidades. Além disso, a própria realidade espacial dos territórios dificulta, também, a cooperação e a integração dos atores. A comunicação é frágil, também, em termos de tempo e de processos, que não são bem definidos. A importância da comunicação é tão recorrente que aparece entre as principais dificuldades enfrentadas, nos territórios Açu-Mossoró e Mato Grande, diferentemente do Sertão do Apodi, que conta com estrutura eficiente de articulação e comunicação a partir do Projeto Dom Helder Câmara.

É importante o reconhecimento da diferença de estrutura para acesso à comunicação e informação no Sertão do Apodi, por meio do Projeto Dom Helder Câmara, tendo em vista que a comunicação, geradora do diálogo e interação, fortalece a rede de atores otimizando confiança e cooperação (LIN, 2001; PUTNAM, 2008). É perceptível a fragilidade nos territórios com maior dificuldade, como no Mato Grande e no Açu-Mossoró, no que se refere a canais e à disponibilidade de recursos. O informante remete o tema da comunicação à burocracia quando se refere a convênios e contratos. Neste quesito, é factível assumir que a presença do Projeto Dom Helder no Sertão do Apodi garante estabilidade de comunicação entre a política pública e o público interessado.

Estes aspectos estruturais de acesso à informação e meios de comunicação apresentados pelos informantes permitem discutir a capacidade dos territórios em se articular mediante o processo de comunicação, tendo em vista que este é formador e fortalecedor das redes. $O$ que se percebe é uma dificuldade na difusão e na ampliação da capilaridade de acesso às informações acerca das políticas públicas que beneficiam os atores territoriais. Este contexto provoca assimetria nas informações, baixa adesão dos atores às políticas públicas e o esvaziamento do colegiado como espaço institucional que representa o Território e sua gestão. Isso provoca pacto no desenvolvimento do Território, visto que inibe o empoderamento dos atores de forma igualitária e democrática. Ademais, o esvaziamento do espaço institucional enfraquece as políticas públicas, pois os atores territoriais não são apenas beneficiários, mas elementos estratégicos no ciclo de políticas públicas, contribuindo para o seu processo de execução e melhoria.

A informação, quanto a conteúdo, assume caráter de assistência técnica, mediante a garantia de acesso a políticas públicas e ao mercado, conforme destaca o Banco Mundial (2003). Os maiores responsáveis por isto, nos territórios analisados, são entidades de apoio e fomento, proporcionando, quanto ao nível, uma informação entre os próprios membros da comunidade, representada aqui pelo Território e seu colegiado, quando orienta e propõe aos membros o diálogo colaborativo na sua função de assistir quanto fomenta, especialmente, uma comunicação e informação em nível entre comunidades a partir da troca de saberes. A comunicação e informação, contudo, sendo 
conduzidas pelas entidades de apoio e fomento, singularmente, apresentam restrições, pois há descontinuidade nos processos de assistência técnica. O Sertão do Apodi apresenta vantagem, pois o Projeto Dom Helder Câmara tem autonomia na execução de projetos de assistência técnica que decorre da mobilização, de capacitação e apoio estrutural.

A garantia de estrutura mínima para a promoção da informação, a partir de mobilização social e do fomento à assistência técnica, é imputada ao Estado (Flores, 2007). Aqui, porém, no que se refere à comunicação e informação, há mais consequências da ausência dos representantes do poder público: as informações das políticas que influenciam o Território não passam pelo colegiado, nem o colegiado tem condições de garantir tal tramitação. Além disto, as entidades que se destacam em proporcionar condições de apoio e fomento para o desenvolvimento só o fazem mediante subsídio financeiro e estrutural e, caso ocorram dificuldades, as informações não fluem além do colegiado, prejudicando os objetivos da política de desenvolvimento territorial.

Estas circunstâncias confirmam as proposições de Coleman (2000), Portes (1998) e Putnam (2008) acerca das redes como estrutura de diminuição da assimetria de informação e de potencialização de atividades e projetos de desenvolvimento. Além disto, é perceptível que, mesmo com todas as dificuldades, é creditada a este espaço a possibilidade de gerar informação, aprendizagem e empoderamento dos atores.

O colegiado é, portanto, reconhecido como espaço de aprendizagem e empoderamento dos indivíduos, capaz de produzir ações coletivas e cooperadas, contudo pouco potencializa o Território tendo em vista dificuldades no fluxo e nos canais de informação entre seus integrantes e, destes, às bases. A infraestrutura física, financeira e de pessoal é limitada, fato que é válido destacar reproduz-se em todo o segmento da agricultura familiar, a exemplo da fragilidade nos serviços de assistência técnica e extensão rural.

De modo geral, a fragilidade é maior em dois territórios, Mato Grande e Açu-Mossoró. O Sertão do Apodi apresenta maior autonomia no processo de comunicação pela estrutura do Projeto Dom Helder Câmara. Enfatiza-se a relação entre as categorias analisadas, pois a dificuldade estrutural influencia diretamente na comunicação e, consequentemente, na cooperação entre atores quanto à constituição de redes. Relação similar está presente no acesso à informação, no tocante aos serviços de assistência técnica e extensão rural, igualmente fragilizados, estando o Sertão do Apodi em condições mais favoráveis pela presença de Organizações Não Governamentais, conforme destacou Cunha (2012), a partir do processo de assistência técnica.

Quadro 2 - Síntese das evidências e respectivas análises

\begin{tabular}{|l|l|}
\hline \multicolumn{2}{|c|}{ CATEGORIA: Redes } \\
\hline Evidências & Análises \\
\hline Em todos os territórios há ênfase & $\begin{array}{l}\text { Aspecto inerente à política em virtude da sua tentativa } \\
\text { nas relações de ligação (indivíduos } \\
\text { de incentivar participação e empoderamento da } \\
\text { com características similares) e ponte } \\
\text { sociedade civil. Permite a troca de informações, recursos } \\
\text { (sujeitos não similares em relação de } \\
\text { horizontalidade) visível nas entidades } \\
\text { de apoio e fomento e sua interação } \\
\text { constante com produtores rurais. }\end{array}$ \\
\hline
\end{tabular}




\begin{tabular}{|c|c|}
\hline $\begin{array}{l}\text { Em todos os territórios as interações } \\
\text { de conexão são mínimas. O } \\
\text { poder público é ator com restrita } \\
\text { participação. }\end{array}$ & $\begin{array}{l}\text { Enfraquece o funcionamento do colegiado e a } \\
\text { formação de capital social, pois tem papel legitimador } \\
\text { e é reconhecido pelos outros atores como indutor das } \\
\text { ações; além disso, institucionalmente é o executor } \\
\text { de políticas públicas e ações coletivas discutidas no } \\
\text { colegiado. }\end{array}$ \\
\hline Baixa diversidade de atores. & $\begin{array}{l}\text { A agricultura familiar é a identidade que aglutina } \\
\text { os atores territoriais, mas outras temáticas além da } \\
\text { produção e comercialização são necessárias para o } \\
\text { desenvolvimento dos territórios e para a formaçãa de } \\
\text { um capital social efetivo. Principalmente por reconhecer } \\
\text { que os atores envolvidos na agricultura familiar têm } \\
\text { baixa capacidade de mobilização. }\end{array}$ \\
\hline \multicolumn{2}{|c|}{ CATEGORIA: Características de Organização Social } \\
\hline Evidências & Análises \\
\hline $\begin{array}{l}\text { Restrita efetividade nas decisões e na } \\
\text { realização de projetos. }\end{array}$ & $\begin{array}{l}\text { Consequência do desenho institucional (norma) da } \\
\text { política em análise. Embora seja uma catalisadora de } \\
\text { outras políticas na constituição dos territórios e de sua } \\
\text { instância operacional - o colegiado - a dependência do } \\
\text { Executivo municipal para a implementação de políticas } \\
\text { públicas e ações coletivas enfraquece o processo } \\
\text { participativo, pois este ator é ausente do colegiado } \\
\text { e executa as políticas independente das discussões } \\
\text { estabelecidas naquela instância. }\end{array}$ \\
\hline Baixa cooperação e confiança. & $\begin{array}{l}\text { Relaciona-se com a evidência anterior. Os atores da } \\
\text { sociedade civil se aproximam da política dos Territórios } \\
\text { da Cidadania enquanto beneficiários e interessados } \\
\text { em outras políticas rurais, mas diversas vezes aquele } \\
\text { espaço de discussão e planejamento não supre as } \\
\text { expectativas geradas pela própria instância participativa } \\
\text { ou evidenciadas no escopo das políticas transversais. } \\
\text { Deste modo, afastam-se do colegiado. }\end{array}$ \\
\hline $\begin{array}{l}\text { Cooperação mantida pela identidade } \\
\text { comum. }\end{array}$ & $\begin{array}{l}\text { Os atores se aglutinam em torno da identidade da } \\
\text { agricultura familiar. Isto ainda é capaz de sustentar a } \\
\text { cooperação e a consequente troca de informações e } \\
\text { compartilhamento de recursos e estrutura, embora } \\
\text { restrita às interações entre sociedade civil e entidades } \\
\text { de apoio e fomento. }\end{array}$ \\
\hline \multicolumn{2}{|c|}{ CATEGORIA: Comunicação e Informação } \\
\hline Evidências & Análises \\
\hline $\begin{array}{l}\text { De modo geral, precárias condições } \\
\text { de acesso à informação e processos } \\
\text { de comunicação. O Sertão do Apodi } \\
\text { apresenta quadro melhor em virtude } \\
\text { de um único ator dispor de estrutura } \\
\text { consistente. }\end{array}$ & $\begin{array}{l}\text { A análise desta evidência demonstra forte } \\
\text { interdependência com as outras. Os colegiados não } \\
\text { detêm estrutura para mobilização e, portanto, limita-se } \\
\text { o alcance das informaçães geradas em seu âmbito. Este } \\
\text { contexto provoca assimetria nas informações, baixa } \\
\text { adesão dos atores às políticas públicas e o esvaziamento } \\
\text { do colegiado, enquanto espaço institucional que } \\
\text { representa o território e sua gestão. } \\
\text { A interdependência consiste na relação entre qualidade } \\
\text { da informação e diversidade dos atores, bem como na } \\
\text { consequência do alcance da informação na mobilização } \\
\text { e cooperação, portanto, na potencialidade do capital } \\
\text { social. } \\
\text { No Sertão do Apodi o projeto Dom Helder Câmara atua } \\
\text { em paralelo à política territorial, mas junto aos mesmos } \\
\text { atores desta política, deste modo consegue suprir as } \\
\text { dificuldades de mobilização e informação. }\end{array}$ \\
\hline
\end{tabular}




\section{CONSIDERAÇÕES FINAIS}

A avaliação dos elementos de capital social - redes, organização social e comunicação/ informação - que circundam o Programa Territórios da Cidadania no Rio Grande do Norte concentrou-se nos colegiados territoriais, estrutura na qual materializam as relações sociopolíticas. É perceptível a limitação de atuação desta instância para fomentar a organização social em favor do desenvolvimento diante da restrita participação do poder público. A ausência de atores que o representam dificulta a execução das deliberações do colegiado em termos de capital social em si. Isto foi percebido, especialmente, em virtude do desenho institucional que não garante a instituição do planejado e deliberado pelos atores territoriais, o que acaba por enfraquecer a própria política territorial. Sem a garantia de ganhos efetivos pelos atores, especialmente aqueles da sociedade civil, há deslegitimação dos espaços criados para participação e, assim, deterioração da confiança em torno da política.

Ademais, não se percebe uma satisfatória cooperação, pois as normas, reforçadoras da confiança e indutoras do processo de articulação coletiva, não levam à interação e à interdependência entre os atores. Pelo contrário, as dispensam no alcance de objetivos da política.

Nos casos em pauta, em que pese a similaridade das condições gerais de estrutura e funcionamento, o Sertão do Apodi apresenta qualidades superiores aos demais tendo em vista sua trajetória de cooperação e articulação social em torno da assistência técnica, aspecto histórico do Território. Este papel tem sido centrado no projeto Dom Helder Câmara. Dessa forma, a estrutura para funcionamento de redes é imprescindível, tendo em vista a capacidade que um único ator, com autonomia de recursos para mobilizar e executar ações no território, tende a gerar benefícios para toda a rede de atores, como visualizado no Sertão do Apodi mediante o Projeto Dom Helder Câmara.

A presença do projeto Dom Helder Câmara que articula, em paralelo ao Território da Cidadania, os mesmos atores da política pública com capacidade de mobilização social e de efetividade de ações, é capaz de fomentar processos de desenvolvimento diferenciados no Sertão do Apodi. Este pode ser fator explicativo, tangenciando a organização social, para que o Território apresente condições de vida e melhores níveis de desenvolvimento que os outros dois aqui abordados, tendo em vista que o acesso à informação, tanto no que tange ao processo de articulação quanto no acesso à assistência técnica, é fator modificador da realidade territorial e aglutinador, passível de prover cooperação entre os atores territoriais e destes com outras instituições direta ou indiretamente vinculadas à política territorial.

Este contraponto da atuação do Projeto Dom Helder Câmara diante de uma política territorial com lacunas em sua atuação demonstra que o investimento em capital social como elemento fomentador de processos de desenvolvimento territorial não ocorre espontaneamente apenas com o estabelecimento de instâncias colegiadas e participativas. Este é um processo que se retroalimenta na estruturação de normas que permitam a cooperação dos atores de fato na execução de políticas públicas, garantindo que sua voz e expectativas sejam efetivadas durante a implementação das decisões em torno de determinada política pública. 


\section{REFERÊNCIAS}

ABRAMOVAY, R. O futuro das regiões rurais. Porto Alegre: UFRGS, 2005.

ATRIA, R. Capital social: concepto, dimensiones y estrategias para su desarrollo. In: ATRIA, R. et al. Capital Social y Reducción de la Pobreza en América Latina y el Caribe: en busca de un nuevo paradigma. Santiago: Comisión Económica para America Latina y el Caribe, 2003.

BANCO MUNDIAL. Questionário integrado para medir capital social. Washington, 2003.

BARDIN, L. Análise de conteúdo. Lisboa: Edições 70, 2004.

BARNEY, Jay B. Looking inside for competitive advantage. Academy of Management Perspectives, v. 9, n. 4, p. 49-61, 1995.

BARNEY, Jay B. Resource-based theories of competitive advantage: A ten-year retrospective on the resource-based view. Journal of management, v. 27, n. 6, p. 643-650, 2001.

BITENCOURT, Claudia; OLIVEIRA, Talita. Dependência e criação de trajetória na organização não governamental parceiros voluntários. Rev. adm. contemp., Curitiba, v. 18, n. 3, p. 351-367, jun. 2014. Disponível em $<$ http://www.scielo.br/scielo.php?script=sci_arttext\&pid=S1415-65552014000300007\&lng=pt\&nrm=iso>. acessos em 24 fev. 2019. http://dx.doi.org/10.1590/1982-7849rac20141708.

BORBA, M. F. S.; GOMES, J. C. C.; TRUJILLO, R. Possibilidades do local num mundo globalizado: perspectivas para o desenvolvimento endógeno. In: BORBA, M. F. S; GOMES, J. C. C. (Org.). Localizando o desenvolvimento: o local e a tradição na busca da sustentabilidade. Pelotas: Embrapa Clima Temperado, 2003. p. 67-98.

BOURDIEU, P. O poder simbólico. São Paulo: Difel; Bertrand Brasil, 1989.

BOURDIEU, P. The Forms of Capital. In: RICHARDSON, J. G. Handbook of Theory and Research for Sociology of Education. New York: Greenwood Press, 1986. p. 241-258.

BRASIL. Referências para o desenvolvimento territorial sustentável. Brasília: Ministério do Desenvolvimento Agrário; Secretaria de Desenvolvimento Territorial, 2005.

BRASIL. Empresa Brasileira de Pesquisa Agropecuária. Centro de Pesquisa Agropecuária de Clima Temperado. Territórios da cidadania: proposta do Ministério do Desenvolvimento Agrário para redução da desigualdade social no meio rural do brasileiro. Disponível em: http://www.cpact.embrapa.br/forum/noticias/index.php. Acesso em: 11 out. 2012.

BUARQUE, S. C. Construindo o desenvolvimento local sustentável: metodologia de planejamento. 4. ed. Rio de Janeiro: Garamond, 2008.

BUARQUE, S. C. Reflexões e proposições de políticas públicas de desenvolvimento territorial. Brasília: IICA, 2012. (Série Desenvolvimento Rural Sustentável, v. 15).

CASTELLS, M.; BORJA, J. As cidades como atores políticos. Revista Novos Estudos. São Paulo, Cebrap, n. 45, p. 152-166, jul. 1996.

COLEMAN, James S. Foundations of social theory. Londres: The Belknap press of Harvard University Press, 1990.

COLEMAN, James S. Social Capital in the Creation of Human Capital. In: LESSER, E. L. Knowledge and Social Capital: Foundations and Applications. Boston, MA: Butterworth-Heinemann, 2000. p. 17-41.

COSTA, F. C. Capital social e o Comitê de Bacia Hidrográfica dos Sinos: um estudo de caso. SEMINÁRIOS EM ADMINISTRAÇÃO FEA-USP, Semead, 8., 2005. São Paulo, 2005.

CUNHA, A. S. R. Metodologias de serviços públicos de Ater: estudo em instituições do Rio Grande do Norte. Natal: UFRN, 2012.

DELGADO, N. G.; BONNAL, P.; LEITE, S. P. Desenvolvimento territorial: articulação de políticas públicas e atores sociais. Rio de Janeiro: IICA; OPPA; CPDA; UFRRJ, 2007.

FLICK, U. Desenho da pesquisa qualitativa. São Paulo: Artmed, 2009.

FLORES, M. La identidad cultural del territorio como base de una estrategia de desarrollo sostenible. Revista Opera, Bogotá: Universidad Externado de Colombia, n. 7, 2007.

FUKUYAMA, F. Confiança: as virtudes sociais e a criação da prosperidade. Rio de Janeiro: Ed. Rocco. 1996. FUKUYAMA, F. A grande ruptura: a natureza humana e a reconstituição da ordem social. Rio de Janeiro: Ed. Rocco, 2000.

GROOTAERT, C. Social Capital: The missing link? The World Bank, Social Capital Initiative. Washington, DC, 1998.

GROOTAERT, C.; BASTELAER, T. Van. Understanding and Measuring Social Capital: A synthesis of findings and recommendations from the Social Capital Initiative. The World Bank, Social Capital Initiative. Washington, DC, 2001.

HEALY, K.; HAMPSHIRE, A. Social capital: a useful concept for social work? Australian Social Work, v. 55, n. 3, p. 227-238, set. 2002. 
KLIKSBERG, B. Capital social e cultura: as chaves esquecidas do desenvolvimento. Programa de Promoção da Reforma Educativa na América Latina e Caribe - Rio de janeiro: Preal Brasil, Séries Preal de Debates, Edição Especial, 2002.

LECHNER, N. Desafíos de un Desarrollo Humano: individualización y capital social. Foro de Desarrollo y Cultura. Organizado por Science Po para Asamblea General del Banco Interamericano de Desarrollo, BID. Paris, mar. 1999.

LIN, N. Building a Network Theory of Social Capital. Social Capital: Theory and Research. New York: Aldine de Gruyter, 2001.

MINTZBERG, Henry; WATERS, James A. Of strategies, deliberate and emergent. Strategic management journal, v. 6, n. 3, p. 257-272, 1985.

MULS, L. M. Desenvolvimento local, espaço e território: o conceito de capital social e a importância da formação de redes entre organismos e instituições locais. Economia, Brasília, v. 9, n. 1, p. 1-21, 2008.

NAVARRO, Z. Desenvolvimento rural no Brasil: os limites do passado e os caminhos do futuro. Estudos Avançados, v. 15, n. 43, p. 83-100, 2001.

PORTELA, M.; NEIRA, I. El papel del capital social en la ayuda al desarrollo: un primer análisis para la Ocde. REM, n. 30, p. 185-208, 2012.

PORTES, A. Social Capital: Its Origins and Applications in Modern Sociology. Annual Reviews of Sociology, vol. 24, p. 1-24, 1998.

PORTES, A., LANDOLT, P. The downside of social capital. The American Prospect, n. 13, maio/jun. 1996. POUPART, J. A pesquisa qualitativa: enfoques epistemológicos e metodológicos. Petrópolis: Vozes, 2008. PUTNAM, R. D. Comunidade e democracia: a experiência da Itália Moderna. 5. ed. Rio de Janeiro: FGV, 2008.

RÜCKERT, A. A.; RAMBO, A. G. Metodologia das escalas geográficas de poder e gestão aplicada aos estudos de desenvolvimento em quatro territórios rurais. CONGRESSO DA SOCIEDADE BRASILEIRA DE ECONOMIA, ADMINISTRAÇÃO E SOCIOLOGIA RURAL - Sober, 45., Londrina, 2007.

SABATINI, Francisco. La segregación social del espacio en las ciudades de América Latina. Inter-American Development Bank, 2006.

SCHMIDT, J. P. Capital social e participação política em Santa Cruz do Sul. In: CORREA, S. Capital social e desenvolvimento regional. Santa Cruz do Sul: Edunisc, 2003. p. 213-263.

SOARES, A. P. A. A relação entre o capital social e o desenvolvimento local: o caso das comunidades rurais de baixo rendimento em Pernambuco. Braga, Portugal: Escola de Economia e Gestão; Universidade do Minho, 2009.

STOLLE, D. The Sources of Social Capital - Generating Social Capital: Civi Society and Institutions in Comparative Perspective. New York: Palgrave Macmillan, 2003.

WALLIS, J.; DOLLERY, B. Social Capital and Local Government Capacity. Australian Journal of Public Administration, v. 3, n. 61, p. 76-85, 2002.

WELLMAN, B.; FRANK, K. Network Capital in a Multilevel World: Getting Support from Personal Communities. Social Capital: Theory and Research. New York: Aldine de Gruyter, 2001.

WOOLCOCK, M. La Importancia del Capital Social para Comprender los Resultados Económicos y Sociales. Poverty Net Library; PRSP; The World Bank, 2001.

WOOLCOCK, M.; NARAYAN, D. Capital Social Implicaciones para la teoría, la investigación y las políticas sobre desarrollo. Poverty Net Library; PRSP; The World Bank, 2002.

YIN, R. K. Estudo de caso: planejamento e métodos. Porto Alegre: Bookman, 2001. 